\title{
USOS SOCIAIS DA ESCRITA: UM ESTUDO SOBRE PRÁTICAS E EVENTOS DE LETRAMENTO NA VIVÊNCIA DE PROFESSORAS ALFABETIZADORAS
}

\author{
Michelle Donizeth Euzébio* \\ Mary Elizabeth Cerutti-Rizzatti**
}

\begin{abstract}
Resumo: Este artigo aborda o fenômeno do letramento. $O$ estudo foi realizado durante dois meses com professores alfabetizadores. Trata-se de abordagem qualitativa de implicações etnográficas que visa responder às seguintes questões: Como se caracterizam os usos sociais da escrita no cotidiano desses professores? Que práticas e eventos de letramento é possivel depreender/descreverem sua vida cotidiana e em seu trabalho? A base teórica é Street (1984, 1988, 2003), Barton (1994), Barton Hamilton e Ivanic (2000), Hamilton (2000) e outros autores dos Novos Estudos do Letramento. Os resultados indicam que os alfabetizadores mencionam eventos de letramento dominantes como parte de sua vida cotidiana remetendo a concepções do modelo autônomo de letramento. Em seu trabalho, por outro lado, mencionam muitos eventos de letramento vernaculares, remetendo a concepções do modelo ideológico de letramento. Dissonâncias dessa ordem sugerem uma ação docente ancorada em modismos pedagógicos e não em construtos teoricamente consolidados nessa área.
\end{abstract}

Palavras-chave: Práticas de letramento. Eventos de letramento. Esfera familiar. Esfera do trabalho. Alfabetizadores.

\footnotetext{
* Doutoranda do Programa de Pós-graduação em Linguística Aplicada da Universidade Federal de Santa Catarina e membro do Núcleo de Estudos em Linguística Aplicada NELA/UFSC. Email: michellidoni@yahoo.com.br

** Professora do Programa de Pós-graduação em Linguística Aplicada da Universidade Federal de Santa Catarina e Vice-Coordenadora do Núcleo de Estudos em Linguística Aplicada - NELA/UFSC. Email: mary.elizabeth@ufsc.br
} 


\section{INTRODUÇÃO}

É possível que uma das mais expressivas ressignificações acerca dos usos da modalidade escrita da língua que emergiram com os estudos do letramento tenha sido a compreensão de que usamos a escrita para diferentes finalidades, nas variadas situações interacionais que têm lugar em nossa história de vida. Dessa compreensão resultou, em boa medida, o entendimento de que as leituras são diversas tanto quanto o ato de escrever é diverso, olhar que colocou em xeque uma visão monolítica do uso da escrita, tomada na imanência e estreitamente comprometida com a erudição e a escolarização.

Esse olhar monolítico, porém, é uma tradição consolidada de tal forma que ainda parece bastante difícil o alargamento das concepções acerca do que seja ler e escrever nas diversas culturas e nos mais variados tempos históricos. Quando Street (1984) chamou atenção para a força da tradição subjacente ao modelo autônomo de letramento seguramente sinalizou para dificuldades dessa ordem. O que chamamos hoje de letramentos dominantes (HAMILTON, 2000a) tende a sinonimizar letramento como fenômeno a despeito das enriquecedoras abordagens sobre o tema que têm tido lugar nas últimas décadas.

Nesse percurso de tempo, os estudos do letramento, paralelamente ou em interface - com os estudos sobre gêneros discursivos (BAKHTIN, 2003 [1952/53]), vêm atentando para as estreitas relações entre os usos da língua e as esferas da atividade humana; eis o olhar para a diversidade e a contraposição a concepções monolíticas e uniformizantes em se tratando desses mesmos usos - e, no caso dos estudos do letramento, no que respeita à modalidade escrita da língua.

Tais teorizações têm repercutido na esfera escolar, quer pela intermediação de documentos oficiais parametrizadores do ensino, quer pela intermediação de cursos de formação inicial ou continuada de professores. O estudo aqui desenvolvido, no entanto, sugere que estamos ainda distantes de uma efetiva apropriação docente desses construtos teóricos, de modo a permitir a professores - nesse caso, alfabetizadores refletir sobre os usos da escrita, nas diferentes esferas da atividade humana, à luz desse mesmo ideário. 
Discutir questões tais é o propósito do presente estudo que, na primeira seção, registra o aporte teórico que sustenta a reflexão e, na segunda seção, apresenta questões de pesquisa e abordagem metodológica, tanto quanto discussão dos dados gerados, fazendo-o sob uma perspectiva qualitativo-interpretativista (MASON, 1996).

\section{LETRAMENTO: UMA INCURSÃO TEÓRICA INICIAL}

Letramento é um conceito multifacetado que, há pouco mais de uma década, tem revelado novos sentidos no que se refere ao uso da modalidade escrita da língua. Sob essa perspectiva, a partir da década de 1980, o conceito de letramento foi ganhando ressignificação, sobretudo com os estudos do letramento e novos estudos do letramento. No entendimento de Street e Lefstein (2007), trata-se de uma abordagem que tem sido particularmente influenciada pela perspectiva etnográfica.

Sob esse ponto de vista, letramento é mais bem compreendido como um conjunto de práticas sociais, passíveis de depreensão a partir de eventos em que as relações intersubjetivas são mediadas por textos escritos (HAMILTON; BARTON; IVANIC, 2000). Barton e Hamilton (1998; 2000) compreendem que existem diferentes letramentos associados a diferentes competências da vida; no entendimento dos autores, as práticas de letramento se erigem a partir de práticas culturais mais amplas. Desse modo, os novos estudos do letramento representam uma nova tradição em considerar a natureza do conceito, focalizando o fenômeno não como um conjunto de competências, mas estando substancialmente implicado nas práticas sociais. No entendimento de Hamilton (2000), nos últimos anos temos visto uma mudança de paradigma nos estudos da escrita nas sociedades contemporâneas. De um modelo psicológico ou cognitivo em que a apropriação e o uso da escrita eram concebidos como um conjunto de habilidades individuais, temos transcendido para uma concepção que toma a escrita no âmbito das práticas socioculturais historicamente situadas.

Escrevem Oliveira e Kleiman (2008, p. 7): 
Os estudos do letramento [...] refletem a inter e a transdisciplinaridade características da pesquisa sobre a escrita e o ensino de língua materna nesse campo do saber e, também, a heterogeneidade de questões e problemas de pesquisa que aí se constituem: possíveis relações existentes entre os estilos cognitivos e as formas de socialização da linguagem; as relações de interdependência entre a fala e a escrita; os condicionantes que contribuem para o desenvolvimento de estilos diferentes de aprendizagem da leitura e da escritura; os processos sócio-históricos e culturais que influenciam os usos da língua escrita; as relações entre sucesso ou insucesso escolar; os significados das políticas de alfabetização e de letramento instituídas nas instâncias governamentais; a educação das minorias; as relações de poder que atravessam as práticas de uso da língua.

Definindo tal acepção como base, compreendemos que diferentes grupos sociais apresentam orientações distintas de letramento. Sob essa perspectiva, letramento (BARTON, 1994; ROJO, 2009; OLIVEIRA, 2009) implica as maneiras pelas quais as diferentes culturas concebem a escrita, o que reverbera nas relações sociais. De acordo com Kleiman (1995, p. 19), "podemos definir hoje letramento como um conjunto de práticas sociais que usam a escrita, enquanto sistema simbólico e enquanto tecnologia, em contextos específicos, para objetivos específicos."

No bojo dessa discussão, cabe aqui referenciar Street (1984; 2003b; 2007) e suas conhecidas proposições acerca dos modelos autônomo e ideológico de letramento. $\mathrm{O}$ autor posiciona-se em favor desse último, definindo o letramento como uso da escrita em termos de práticas sociais concretas. O modelo autônomo, para o antropólogo, considera a escrita em sua imanência, desvinculada de contextos de uso. Nessa concepção, as funções da linguagem são afetadas pelo domínio da escrita, principalmente no que diz respeito a funções lógicas. Desse modo, a oralidade seria secundária no que tange ao uso dessas funções, uma vez que da escrita dependeria a capacidade cognitiva de abstrair. Nessa perspectiva, há uma dicotomização entre a escrita e a oralidade, em que a primeira é regida pela racionalidade e pela lógica, ao passo que a segunda remete a funções interpessoais da linguagem. 
Nesse modelo, no entendimento de Street (1984, 2003b), os processos mentais orais se apresentariam de forma mais simples, estando voltados para exterioridade e subjetividade, contrariamente aos processos mentais característicos da escrita que seriam mais complexos e inovadores. De acordo com Street (1984), esse modelo foi instaurado em decorrência de propósitos políticos específicos. Sob essa perspectiva, o fenômeno do letramento seria tomado como confirmador da teoria da grande divisa entre "povos lógicos" e "povos pré-lógicos".

Em oposição ao modelo autônomo, Street (1984) propõe o modelo ideológico de letramento. Essa vertente pressupõe o letramento tomado como prática social e não apenas como produto técnico e neutro, em que o contexto é determinante na maneira como os indivíduos lidam com a escrita. Sob esse ponto de vista, o letramento está vinculado ao contexto social em que se inserem os sujeitos. Por meio desse modelo, Street (1984; 2003b) e Street e Lefstein (2007) tomam letramento em termos de práticas sociais concretas, sendo que, em seu entendimento, não deve haver dicotomização entre a comunicação oral e a escrita.

Conforme o autor, tais modalidades devem estar ligadas a aspectos que ocorrem naturalmente na cultura humana; o fenômeno do letramento deve ser visto na perspectiva do uso e não da tecnologia, dado que a escrita é utilizada de maneira diferente entre as culturas, cada qual dessas duas modalidades da língua - oralidade e escrita - com suas finalidades específicas. Sob esse olhar de Street $(1984 ; 2003)$ e de Street e Lefstein (2007), o modelo ideológico foi criado para entender a lógica dos usos sociais da escrita nas diferentes culturas. Street e Lefstein (2007) compreendem que tal modelo ideológico faculta um olhar culturalmente sensível aos usos da escrita, atentado para sua variabilidade ${ }^{1}$ nos diferentes entornos sociais.

Rojo (2009) ressalta que o termo letramento implica os usos e as práticas sociais às quais a escrita se presta, tanto em contextos valorizados

\footnotetext{
${ }^{1}$ Street $(2000 ; 2010)$ considera que a proposição de que os letramentos são múltiplos não pode ser confundida com o entendimento de que haveria um letramento correspondente a cada cultura, tanto quanto não pode espraiar-se de modo tal que denegue as práticas sociais como o enfoque dessa proposição teórica, a exemplo do que tem acontecido, em muitos contextos, com o conceito de letramento digital ou midiático, situações em que, não raro, as tecnologias se sobrepõem às práticas.
} 
como não valorizados, recobrindo os mais variados espaços, tais como família, escola, igreja, mídias. De acordo com a autora, as mais recentes abordagens acerca desses estudos têm apontado para a forma heterogênea na qual as práticas sociais de leitura e escrita estão presentes, uma vez que há letramentos diferentes associados a diferentes domínios da vida (BARTON; HAMILTON; IVANIC, 2000). Acerca disso, Kleiman (2008, p. 18) argumenta que os "estudos do letramento adotam um modelo situado das práticas de uso da língua escrita", visto que, nessa perspectiva, qualquer aspecto descritivo ou explicativo acerca dos usos da modalidade escrita implica todos os eventos que compõem a situação comunicativa. De acordo com Street, (2003a, p. 77, tradução nossa), esse posicionamento traz implicações para

o reconhecimento dos múltiplos letramentos, que variam no tempo e no espaço, mas que são também contestados nas relações de poder. Assim, os NLS [Novos Estudos do Letramento] não pressupõem coisa alguma como garantida em relação aos letramentos e às práticas sociais com que se associam, problematizando aquilo que conta como letramento em qualquer tempo-espaço e interrogando-se sobre "quais-letramentos" são dominantes e quais são marginalizados ou de resistência.

O conceito de letramento, sob essa perspectiva, passa a ser designado no plural. Hamilton (2000b, p. 1, tradução nossa) escreve: "Essa mudança tem implicações na forma como nós trabalhamos com o letramento." A autora discute, em seus estudos, os letramentos dominantes e os letramentos locais ou vernaculares. No entendimento de Hamilton (2000b) e de Barton e Hamilton (1998), os letramentos dominantes estão associados a organizações formais, tais como escolas, igrejas, locais de trabalho, comércio, nos quais estão previstos agentes como, por exemplo, professores, especialistas, padres, dentre outros. Já no que tange aos letramentos vernaculares, os autores compreendem que são essencialmente aqueles que não são regulamentados ou sistematizados por regras e procedimentos formais de instituições sociais, mas têm sua origem nos propósitos da vida cotidiana (BARTON; HAMILTON, 1998; HAMILTON 2000a). 
Na concepção de Barton, Hamilton e Ivanic (2000, p. 8, tradução nossa), "Práticas de letramento são padronizadas por instituições sociais e relações de poder, e alguns letramentos são dominantes, mais visíveis e influentes do que outros." Hamilton (2000b, p. 4, tradução nossa) ressalta, no entanto, que "Letramentos vernaculares e institucionais não são independentes e separados por categorias de atividade, mas estão em diálogo, e as fronteiras entre eles são permeáveis e mutáveis."

Barton (1994) também compreende que letramento deve implicar usos sociais que as pessoas fazem da escrita e não apenas seu aprendizado formal dessa modalidade da língua, considerando necessariamente a vida diária e as atividades em que os indivíduos estão envolvidos. Desse modo, no âmbito da visão social do letramento, Barton (1994) entende que as pessoas se valem de diferentes tipos de letramento, referentemente aos usos que fazem da escrita, o que está associado aos diversos domínios da vida. Nesses domínios, tangentes a culturas e períodos históricos distintos, podemos perceber diferentes tipos de letramento, tanto quanto podemos perceber que as práticas de letramento são situadas nas relações sociais (BARTON; HAMILTON; IVANIC, 2000).

$\mathrm{O}$ autor propõe, em seus estudos, ancorado em trabalhos anteriores de Shirley Heath (1982) e Brian Street (1984; 1988), dois componentes do fenômeno do letramento: os eventos e as práticas de letramento. Para o autor (1994, p. 37, tradução nossa), "Eventos de letramento são as atividades em que o letramento tem um papel [...] Práticas de letramento são as diferentes formas como cada cultura utiliza a escrita, [práticas] nas quais as pessoas se baseiam num evento de letramento." No entendimento de Barton e Hamilton (2000), as práticas de letramento são formas gerais de cultura, vivências que ancoram os usos da modalidade escrita e por meio das quais os indivíduos interagem durante suas vidas; essas práticas, no entanto, não são unidades observáveis de comportamento, uma vez que envolvem valores, atitudes, sentimentos e relações sociais. Já os eventos de letramento, segundo os autores, "são episódios observáveis que resultam de práticas e são moldados por essas mesmas práticas." (BARTON; HAMILTON 2000, p. 8, tradução nossa). 
Sob essa perspectiva, tais práticas constituem processos intrassubjetivos derivados de processos intersubjetivos, incluindo cognições compartilhadas, representadas em ideologias e identidades sociais. As práticas são formadas por regras que regulam o uso e a distribuição de textos, recomendando quem pode produzir e ter acesso a eles. Elas são mais bem compreendidas como vivências derivadas das relações entre indivíduos dentro de grupos e comunidades do que como um conjunto de propriedades contidas no universo individual.

Os eventos de letramento, por sua vez, na compreensão de Barton e Hamilton (1998; 2000), são atividades em que o letramento exerce um papel. Os eventos são episódios observáveis que surgem das práticas. De acordo com os autores, alguns eventos estão ligados à sequência de rotinas que podem consistir em procedimentos formais e expectativas de instituições sociais, tais como local de trabalho, escolas e organizações de assistência; outros eventos instituem-se em vivências mais informais, que têm lugar no lar, na rotina diária.

Hamilton (2000a), ao discutir os conceitos de práticas e eventos de letramento, propõe um entendimento mais global para esses fenômenos. A autora, em seu estudo, fez uma análise de traços visuais em fotografias de jornais, a fim de estudar práticas e eventos de letramento nas sociedades contemporâneas. Hamilton (2000a) assinala que essas imagens contêm quatro elementos visíveis dos eventos de letramento que serviram de ponto de partida para sua pesquisa, tais como participantes, ambientes, artefatos $e$ atividades. Já as práticas de letramento, no entendimento da pesquisadora, só podem ser inferidas a partir de evidências observáveis, uma vez que incluem apenas recursos invisíveis, tais como conhecimentos e sentimentos, que encarnam fins sociais e valores, sendo parte de uma constante mudança de contexto, ambas de natureza espacial e temporal.

As considerações acerca dos usos sociais da escrita até aqui alinhavadas motivaram-nos a realizar este estudo, no qual buscamos descrever eventos de letramento que ocupam lugar na vivência diária e no trabalho de um grupo de professoras alfabetizadoras do Município de Garopaba/SC - depreendendo práticas de letramento subjacentes a tais eventos. 


\section{EVENTOS DE LETRAMENTO: A ESCRITA NA ESFERA DOMÉSTICA E NA ESFERA DO TRABALHO}

A nova concepção acerca dos estudos do letramento de que tratamos na seção anterior ancora o estudo que descrevemos nesta seção. De acordo com Hamilton (2000), a essência dessa abordagem consiste na compreensão do letramento não em termos de níveis de habilidades, mas em termos de práticas sociais e comunicativas com as quais os indivíduos se envolvem em vários domínios de sua vida. Concordamos com Kramsh (1998, p. 9, tradução nossa) quando afirma:

$\mathrm{Na}$ dimensão social e histórica [...], a cultura é heterogênea. Membros de uma mesma comunidade discursiva têm biografias e experiências de vida diferentes. Eles podem diferir em idade, sexo ou etnia, eles podem ter diferentes opiniões políticas. Além disso, as culturas mudam ao longo do tempo [...]. Culturas não são apenas heterogêneas e em constante mudança, mas são o local da luta pelo poder e pelo reconhecimento.

Em nossa concepção, uma das questões mais relevantes para os estudos do letramento é compreender a lógica dos usos sociais a que a escrita se presta. Para tanto, este estudo caracteriza-se como uma abordagem qualitativa interpretativista, focalizada na forma como o mundo social é entendido, experimentado ou produzido (MASON, 1996). Na compreensão de Mason (1996), a pesquisa qualitativa tem como objetivo produzir entendimentos construídos com base em dados ricos, contextuais e detalhados; há mais ênfase na forma holística de análise e, nesse sentido, na explicação do que em traçar padrões, tendências e correlações. André (2008) converge para esse olhar interpretativista e atenta para a importância de estudos qualitativos de implicações etnográficas em se tratando do universo educacional, contexto em que o pesquisador precisa envolver-se de modo mais efetivo com a realidade estudada para construir inteligibilidades para os fenômenos focalizados. 
Nosso objetivo, neste estudo, foi descrever eventos de letramento que têm lugar na vivência de um grupo de professoras alfabetizadoras do Município de Garopaba/SC - depreendendo práticas de letramento subjacentes a esses eventos e tomando esses eventos nas esferas doméstica e do trabalho. Assim, o estudo teve como mote as seguintes questões: Como se caracterizam os usos sociais da escrita no cotidiano dessas professoras? Quais práticas e eventos de letramento é possível depreender/descrever nesse cotidiano - na esfera doméstica e do trabalho? O processo de geração de dados implicou a utilização de instrumentos característicos da pesquisa qualitativa, tais como observação, análise documental e entrevistas. A interação estendeu-se por dois meses e foi feita de modo a depreender as concepções sobre os usos da escrita no cotidiano das três professoras alfabetizadoras participantes do estudo, assim como na busca por depreender/descrever as práticas e eventos de letramento que se eliciam/visibilizam nesse cotidiano, quer em casa, quer no trabalho. Baseado em teorizações de Hamilton (2000a) acerca das práticas e eventos de letramento, o processo de pesquisa teve como foco os elementos visíveis das práticas de letramento, tais como participantes, artefatos, ambientes e atividades e os elementos não visíveis das práticas de letramento, tais como participantes ocultos, domínios, recursos e rotinas.

Hamilton (2000a) registra que os participantes abrangem indivíduos que interagem com materiais escritos; já os ambientes correspondem às circunstâncias físicas imediatas nas quais a interação acontece; os artefatos, por sua vez, consistem em ferramentas materiais e acessórios envolvidos na interação e, por fim, as atividades correspondem às ações realizadas pelos participantes nos eventos de letramento.

Os participantes ocultos, segundo Hamilton (2000a), correspondem a outras pessoas ou grupo de pessoas presentes nas relações sociais; o domínio faz referência às práticas dentro das quais o evento acontece; os recursos compreendem os aspectos trazidos para as práticas de letramento, tais como valores não materiais, compreensões, sentimento; e, por fim, as rotinas consistem em regras de apropriação, ou seja, os indivíduos que podem ou não engajar-se em atividades particulares. 
A realização deste estudo envolveu três professoras alfabetizadoras que lecionam em escolas de Ensino Fundamental no município de Garopaba, SC. A primeira participante, doravante $\mathrm{P}^{2}$, tem 39 anos e leciona no município desde 1991. Formou-se em Pedagogia em 2004 e, recentemente, concluiu um curso de Pós-Graduação em nível de Especialização. A segunda participante, aqui referida como P2, tem 35 anos e atua na docência desde 1994. Essa professora, assim como P1, recentemente concluiu o curso de Pós-Graduação em nível de Especialização, e concluiu a graduação em Pedagogia em 2002. Já a terceira participante deste estudo, P3, tem 33 anos e leciona nos primeiros anos das séries iniciais há cinco anos. Finalizou a Graduação em Pedagogia em 2007 e, atualmente, está cursando Pós-Graduação em nível de Especialização.

Na longa interação que mantivemos com cada uma das profissionais, por ocasião das entrevistas semiestruturadas, das visitas e das interações ao longo do tempo de pesquisa, perguntamos às professoras se, em seu cotidiano, costumam ler livros, jornais, folhetos de loja ou supermercado, revistas, bíblias e se escrevem listas de compras, cartas, bilhetes ou recados, receitas, entre outros artefatos que instituem eventos de letramento. As participantes responderam que grande parte desses eventos de letramento que apresentamos compõe seu cotidiano. Quando, porém, questionadas acerca de quais desses materiais escritos usam mais frequentemente, evidenciam um olhar bastante voltado para os eventos dos letramentos dominantes. P1, nesse sentido, enuncia:

(1) Eu leio muitas revistas, porque gosto de estar informada das notícias sobre educação e livros diversos. Eu leio alguns infantis para o meu filho, na escola; também gosto dos livros de autoajuda, principalmente do Augusto Cury.

\footnotetext{
${ }^{2}$ Estamos cientes de que, em estudos com implicações interpretativistas, evitam-se, de hábito, codificações numéricas. Optamos, porém, por infringir essa tendência em razão da artificialidade que tributamos a nomeações fictícias dos participantes. Entre uma e outra inconveniência, optamos pela numeração.
} 
P2 menciona calendário, mas, em seguida, focaliza o livro e se atém a ele como o suporte de excelência na habituação em leitura:

(2) Calendário, sem dúvida, porque minha função exige para o meu trabalho e também livros infantis, porque tenho contado histórias diariamente para minha filha. Tenho apostado todas as fichas para que ela desenvolva o hábito de leitura. Também leio os livros para minha profissão.

P3 também se atém aos letramentos dominantes; enuncia: (3) Eu leio algumas revistas de educação na internet, material didático. Eu leio mesmo é material da área da educação. A Bíblia eu leio também frequentemente. Cabe aqui referenciar Hamilton (2000b) a respeito da forma como os indivíduos hierarquizam alguns materiais escritos em detrimento de outros. Ao que parece, as enunciações das professoras estão amplamente ancoradas em discursos oriundos de instituições de prestígio, o que implica associação com os já mencionados letramentos dominantes, tal qual suscitado nos estudos de Hamilton (2000b). Seguramente, devido à função que exercem em suas vidas profissionais, tais professoras fazem uso desses tipos de materiais, mas é difícil crer que leituras relacionadas aos letramentos vernaculares não sejam frequentes em atividades cotidianas que se valem da escrita; e elas mesmas reconhecem que os artefatos escritos que mencionamos fazem parte de sua rotina, mas, ao se manifestarem sobre eles, recortam os artefatos que compõem eventos nos letramentos dominantes, a exemplo de livros, revistas, Bíblia. Oliveira (2010, p 334.) compreende que "É evidente que o letramento [...] [ligado às instituições de prestígio] goza de legitimação e, em razão disso, é visto como parâmetro para a avaliação dos letramentos locais."

Quando as interpelamos acerca do que mais gostavam de ler e do que menos gostavam de ler, a menção a eventos nos letramentos dominantes se mantém. P1 diz: (4) Gosto muito de ler historinhas infantis para meu filho e meus alunos. Ah, eu não tenho interesse por noticias esportivas nos jornais. P3, por sua vez, enuncia: (5) Eu gosto de ler mesmo é livros assim da área, produção de texto, essas coisas assim da área, do meu trabalho. Não gosto muito de ler na internet. 
Parece explícita a valorização dos letramentos dominantes, com a focalização em eventos de letramento voltados à erudição, o que inferimos decorrer da prevalência, historicamente e, sobremodo na esfera escolar, de concepções de letramento legitimadas pela cultura mainstream, em um processo de opacidade da diversidade cultural. No entendimento de Street (2003), essa abordagem impõe conceitos hegemônicos de letramento a culturas tidas como periféricas. De acordo com Kramsch (1998), a cultura implica processos de inclusão e exclusão, a que subjazem relações de poder e de controle.

A autora escreve:

só os poderosos decidem quais valores e crenças serão valorizados e adotados por um grupo, quais eventos históricos vale comemorar, que futuro vale imaginar. Culturas, especialmente culturas nacionais, ressoam com as vozes dos poderosos, e são preenchidas com os silêncios dos impotentes. Ambas, as palavras e seus silêncios, contribuem para moldar a [...] cultura. (KRAMSH, 1998, p. 9, tradução nossa).

Ainda com relação às preferências ou não por leituras de um tipo ou de outro, a resposta enunciada por P2 merece um olhar cuidadoso em se tratando de nosso foco de estudo. Ao ser interpelada acerca de tal questão, a resposta da professora sugere sinonímia entre o ato de ler e ler artefatos típicos dos letramentos dominantes, mencionando o conflito que historicamente mantém com [esse tipo de] a leitura.

(6) Não tenho um gosto específico de leitura. Na verdade sei que não tenho esse hábito bem desenvolvido, não faço leitura com prazer; na maioria das vezes, leio por obrigação. Não suportava aqueles livros da faculdade, tipo Bourdieu; já tentei adquirir esse hábito, até assinei a Veja, mas no final não li nada. O que eu costumo ler mesmo é sobre a exigência da minha função.

Parece flagrante, nesse excerto, a dissociação entre a natureza de leituras empreendidas no processo de formação inicial e leituras requeridas para o exercício da função docente: Bourdieu insere-se nessa fala como uma realidade flagrantemente distante de implicações dos fazeres 
pedagógicos. A resposta de $\mathrm{P} 2$, em nosso entendimento, traz subjacentes os recursos carreados para as práticas de letramento, o que remete, sob vários aspectos, aos constituintes não visíveis de tais práticas, tal qual suscitado nos estudos de Hamilton (2000). Esses constituintes implicariam a influência da escola - e da sociedade como um todo - na construção de uma concepção que compreende como leitura apenas a leitura do que corresponde à valoração mainstream.

Segundo Hamilton (2000), os eventos de letramento são a ponta do iceberg, ao passo que as práticas de letramento constituem a base, as quais implicam valores não materiais, compreensões, sentimentos e ideologias. Assim, a caracterização dos eventos de letramento dos quais essas alfabetizadoras participam é ancorada por suas práticas: o que leem e o que não leem deriva da base do iceberg, ou seja, da natureza das práticas de letramento que construíram ao longo de sua historicidade.

$\mathrm{O}$ discurso axiologicamente marcado acerca dos letramentos dominantes, tão recorrente nas respostas que obtivemos e nas situações de que participamos nessas interações, aparece também nas respostas enunciadas pelas professoras referentemente à questão: o que gostavam de escrever e não gostavam de escrever. P1 enuncia: (7) Escrevo pouco, mas gosto de escrever incentivos para meus alunos. Não gosto de, no final do bimestre, fazer aquele parecer descritivo.

P2, por sua vez, relatou adorar escrever e revelou não ter preferências, escreve de acordo com as necessidades de sua função. Já P3 disse gostar muito de escrever sobre questões tais como planejamento das aulas, atividades para os alunos. Mais uma vez, aqui, como já mencionamos, as respostas enunciadas evocam, em alguma medida, o discurso prototípico proveniente das instituições de prestígio, tão entranhadas no ideário popular. Nenhuma das alfabetizadoras mencionou o ato de escrever associado a questões corriqueiras do cotidiano, a eventos correspondentes aos letramentos vernaculares. Eis, aqui, em nosso entendimento, o fenômeno que Street e Lefstein (2007) focalizam ao discutir as estreitas relações entre heranças do modelo autônomo de letramento e valorações da escrita depreensíveis no ideário do senso comum. 
Quando lhes solicitamos para falarem sobre as leituras que acham mais difíceis, P1 mencionou artefatos dos letramentos dominantes, mas possivelmente não tão comprometidos com a erudição, ao alegar não entender bulas de remédio e manuais de instrução, enunciando: (8) Ai, a leitura de bula de remédio é muito complexa; só os médicos mesmo para conseguir entender. Também não entendo muito manuais de instrução. P2, por sua vez, reiterou o foco nos letramentos dominantes: (9) Acho que a Bíblia muito complicada. Várias vezes já li repetidamente e não consegui perceber qual é a mensagem da leitura. P3, da mesma forma, mantém o comportamento de foco nos letramentos dominantes imbricados com a erudição, ao relatar que acha muito difíceis os textos filosóficos.

Quando questionamos acerca da função da escrita na sociedade de hoje, reitera-se a compreensão permeada pelo modelo autônomo de letramento. P1 enuncia: (10) A escrita tem uma função muito importante na sociedade. Se construirmos bom leitores, teremos cidadãos capazes de escrever, interpretar, refletir. P2, por sua vez, diz: (11) Vivemos em uma sociedade letrada ${ }^{3}$, como imaginar então uma pessoa que não domina a leitura e a escrita? Já P3 enuncia: (12) É fazer o indivíduo perceber que pode levar os conhecimentos adquiridos ao alcance das pessoas.

Novamente, as enunciações das participantes deste estudo parecem secundarizar o papel da escrita na organização da vida diária e remetem às discussões de Street $(1984 ; 2000 ; 2003 ; 2010)$ acerca do modelo autônomo de letramento, o que, seguramente, nos faz crer, tem uma estreita relação com o universo do trabalho. No entendimento de Oliveira (2010, p. 329):

Enxergar o letramento como algo 'singular' é esquecer que a vida social é permeada por linguagem de múltiplas formas e destinada a diferentes usos. Nela, são veiculados gêneros diversos que são praticados por diferentes pessoas nas mais diversas atividades sociais, orientadas a partir de propósitos, funções, interesses e necessidades comunicativas específicas, não obstante a compreensão de que alguns textos são considerados canônicos e, por isso, mais legitimados que outros, socialmente. E é exatamente porque se constitui como algo 'plural' que vale a pena problematizar,

\footnotetext{
${ }^{3}$ Letrada, aqui, parece sugerir escolarizada e não grafocêntrica.
} 
examinando as diversas facetas que o constituem e as razões por que esse fenômeno tem se tornado um verdadeiro 'campo de batalha.

Após o delineamento dos dados discutidos até aqui, parece notório que as respostas das participantes deste estudo, em sua maioria, no que tange às atividades cotidianas nas quais se valem da escrita, mencionam eventos de letramento provenientes das esferas escolar e acadêmica, eliciando a força de concepções do modelo autônomo entranhadas nas relações sociais. Diante desse quadro e conferindo um desdobramento ao estudo que não havia sido previsto inicialmente - quando o projetamos, nosso objetivo era descrever eventos de letramento do dia a dia das professoras, sem implicações mais efetivas com a esfera do trabalho -, decidimos empreender uma nova interação com as docentes, a fim de depreender de que modo os eventos de letramento mencionados por tais professoras repercutem em suas práticas escolares. Para tanto, em nova interação, pedimos a elas que explicitassem suas vivências escolares com os alunos no que concerne aos usos de materiais escritos. Interpelada acerca de tal questão, P1 diz:

(13) Trabalho com cartazes, mural de informações, jornais, revistas, convites. Acredito que a escola deva trabalhar com textos funcionais como bilhetes, convites, histórias em quadrinhos. Os textos devem ser coerentes com a realidade do aluno.

P2, por sua vez, enuncia:

(14) Olha, a leitura é muito ampla e certamente não nos damos conta de como é importante os diversos tipos e gêneros textuais. Eu trabalho com materiais que façam parte do contexto social deles, fazendo pesquisas de preço em supermercados, rótulos de embalagem, jornal, revista, materiais que façam parte da vida diária deles.

Já P3 disse:

(15) Eu gosto de trabalhar com revista científica, cardápio, convite, folheto de supermercado. Nós, professores, temos que ter 
consciência que existem gêneros de diferentes esferas de circulação e que é necessário trabalhar com materiais que façam parte do cotidiano dos alunos.

Importa destacar que boa parte desses materiais escritos estão associados aos letramentos vernaculares mencionados nos estudos de Hamilton (2000b). Ao que parece, as respostas das professoras referentemente ao que seja ler e escrever nas esferas escolar e doméstica mostram-se substancialmente divergentes. Desse modo, cabe a pergunta: $\mathrm{O}$ que levaria tais professoras a hierarquizarem alguns tipos de leitura e escrita na esfera familiar e a explicitar o uso de materiais escritos recorrentes na organização da vida diária na esfera escolar? Temos razões para acreditar que haja subjacência de conceitos teóricos no discurso prototípico dessas professoras no que concerne aos artefatos que têm lugar na esfera do trabalho. Talvez esse comportamento explicite uma popularização de referenciais teóricos acadêmicos e institucionais, o que converge com as discussões empreendidas por Oliveira (2010) acerca das concepções advindas dos Parâmetros Curriculares Nacionais (PCNs) e do impacto dos processos formativos oferecidos aos professores em nível nacional. De acordo com a autora, a fala dos educadores, atualmente, nunca esteve tão cheia de orientações teóricas reduzidas a modismos no discurso escolar, quer nos grandes centros educacionais, quer em regiões mais afastadas do Brasil.

Em nossa compreensão, tanto documentos oficiais quanto cursos de formação baseados em tais documentos sugerem que professores tomem a língua como objeto social, o que implica a inserção dos mais variados materiais escritos nas práticas escolares, dentre os quais, materiais que circulem na sociedade nas mais diversas atividades do cotidiano. Sob essa perspectiva, o movimento proposto é levar as competências extraescolares para o universo escolar; ao que parece, as respostas dissonantes enunciadas pelas professoras referentemente ao uso de materiais escritos nas esferas escolar e doméstica sinalizam para uma incompreensão de tal movimento, o que sugere, em nosso entendimento, uma inapropriação do eixo subjacente aos referenciais teóricos implicitados na inserção dos letramentos vernaculares no espaço escolar. 
Quando interpeladas sobre a presença da escrita em seu cotidiano, mencionam eventos de letramento estereotípicos, muito vinculados à erudição e à cultura mainstream. Já, quando interpeladas sobre a presença da escrita em seus fazeres pedagógicos parecem agenciar um conjunto de conhecimentos de natureza metodológica sobre o que se deve fazer na escola hoje. Se essa análise procede em alguma medida, parece-nos haver um equívoco significativo na apropriação dos que-fazeres escolares. Levar gêneros discursivos (BAKHTIN, 2003 [1952/53]) diversos para a sala de aula, propondo - no que respeita à escrita - aos alunos eventos de letramento de toda ordem só faz sentido se esse movimento for compreendido como a presença das práticas sociais - dominantes e vernaculares - no ambiente escolar. $\mathrm{O}$ fato de essas alfabetizadoras mencionarem, no ambiente extraescolar, apenas eventos vinculados aos letramentos dominantes parece sugerir que a valoração de eventos de âmbito vernacular valha menção apenas em nome de uma ação metodológica escolar. Se assim o for, parece-nos não ter havido efetiva apropriação teórica acerca dos postulados que os estudos do letramento trouxeram para que se conceba a modalidade escrita de um modo mais amplo; o que parece haver aqui é a internalização de novos que-fazeres pedagógicos tomados como modismos que grassam na área, sem maior aprofundamento teórico acerca das implicações praxiológicas desses mesmos que-fazeres.

Oliveira (2010, p. 327) registra:

Na busca de uma apropriação que não se efetivou, o professor acaba desenvolvendo um trabalho intuitivo que mistura práticas tradicionais com um discurso pretensamente inovador, caracterizado por entendimentos equivocados. E não poderia ser de outra maneira! Como poderiam ter um entendimento claro e se sentirem seguros acerca desses novos princípios se a própria Academia os reconhece como tão complexos, sendo ainda foco de acirrados debates por parte de seus membros? Transformar 'saberes científicos' em 'saberes a serem ensinados' na práxis escolar não é um trabalho fácil!

Esses dados, em nossa compreensão, suscitam olhares mais cautelosos acerca das relações entre efetiva apropriação conceitual e ação 
pedagógica, instigando a reflexão acerca da forma como as teorizações sobre o fenômeno do letramento - e, nesta discussão, por extensão, as teorizações sobre gêneros discursivos - têm (ou não) efetivamente contribuído para a construção de novos níveis de excelência na educação básica em se tratando do trabalho com a escrita.

\section{CONSIDERAÇÕES FINAIS}

A interação com as educadoras participantes deste estudo leva-nos a inferir que, ao responderem a nossa interpelação sobre a presença da escrita em sua vida diária, as alfabetizadoras parecem se pautar em concepções prototípicas sobre a modalidade escrita da língua e suas finalidades sociais, concepções que remetem ao modelo autônomo de letramento tanto quanto remetem à prevalência dos letramentos dominantes. Movimento oposto parece emergir quando interpelamos tais participantes de pesquisa sobre que usos da escrita ocupam as aulas que ministram a seus alunos. Aqui, surgem os letramentos vernaculares, em uma visível interface com teorizações que grassam em cursos de formação e em documentos oficiais acerca da necessidade de levar gêneros discursivos de toda ordem para a sala de aula. Em nossa compreensão, essa dissonância sugere, sob vários aspectos, uma apropriação bastante parcial do ideário teórico que subjaz aos documentos oficiais e à literatura da área contemporaneamente; talvez não devamos falar em apropriação efetivamente, mas na repetição de comportamentos que têm virado modismos pedagógicos, tal qual adverte Oliveira (2010).

Se essa reflexão procede em alguma medida, importa haver, nos centros de formação docente, estudos acerca do espectro que se desenha entre repetição de estratégias didático-pedagógicas amplamente disseminadas e apropriação teórica efetiva na sustentação da ação pedagógica. O movimento que vemos desenhado nessa interação com as alfabetizadoras participantes deste estudo suscita um olhar mais cuidado para a forma por meio da qual teorizações acadêmicas e diretrizes institucionais têm chegado efetivamente às escolas, bem como para o eventual impacto que tenham tido nos contextos de escolarização formal. 


\section{REFERÊNCIAS}

ANDRÉ, M. E. D. A. de. Estudo de caso em pesquisa e avaliação educacional. 3. ed. Brasília: Liber Livro, 2008.

BAKHTIN, M. Os gêneros do discurso. In: . Estética da criação verbal. Trad. de Paulo Bezerra. 4. ed. São Paulo: Martins Fontes, 2003 [1953/1954]. p. 261-306.

BARTON, D. Literacy: an introduction to the ecology of written language. Cambridge/USA: Blackwell, 1994.

; HAMILTON, M. Local literacies. London and NY: Routledge, 1998. ; _ _ _ IVANIC, R. Situated literacies. London: Routledge, 2000.

BRASIL. Parâmetros Curriculares da Educação Nacional - Língua Portuguesa. Secretaria de Educação Fundamental. Brasília/DF, 1998.

HAMILTON, M. Expanding the new literacy studies: using photographs to explore literacy as social practice. In: BARTON, David; HAMILTON, Mary; IVANIC, Roz (Org.) Situated literacies. London: Routledge, 2000. p.56-87.

. Expanding the new literacy studies: using photographs to explore literacy as social practice. In: BARTON, D.; HAMILTON, M.; IVANIC, R. (Org.)

Situated literacies. London: Routledge, 2000b. p. 89-102.

; BARTON, D.; IVANIC, R. (Orgs.). Worlds of literacy. Clevedon: Multilingual Matters, 1993.

HEATH, S. B. What no bedtime story means: narrative skills at home and school. In: DURANTI, A. (Org.) Linguistic anthropology: a reader. Oxford: Blackwel, 2001 [1982], p. 318-342.

KLEIMAN, A. (Org.) Os significados do letramento: uma nova perspectiva sobre a prática social da escrita. Campinas: Mercado de Letras, 1995.

. Letramento no local de trabalho: o professor e seus conhecimentos. In:

OLIVEIRA, M. do S.; KLEIMAN, A. Letramentos múltiplos. Natal/RN:

UDUFRN, 2008. p. 17-37.

KRAMSCH, C. Language and culture. Oxford/New York: Oxford University Press, 1998. Press, 1993.

. Context and culture in language teaching. Oxford/New York: University

MASON, J. Qualitative researching. London: SAGE Publications, 1996.

OLIVEIRA, M. do S.; KLEIMAN, A. Letramentos múltiplos. Natal,RN:

UDUFRN, 2008. 
. Projetos: uma prática de letramento no cotidiano do professor de língua materna. In: OLIVEIRA, M. do S.; KLEIMAN, A. Letramentos múltiplos. Natal,RN: UDUFRN, 2008. p. 93-118.

. Gêneros textuais e letramento. Revista Brasileira de Linguística Aplicada, v. 10, p. 325-345, 2010.

ROJO, R. Letramentos múltiplos, escola e inclusão social. São Paulo: Parábola Editorial, 2009.

STREET, B. Literacy in theory and practice. Cambridge: Cambridge University Press, 1984.

. Literacy practices and literacy myths. In: SALJO, R. (Org.) The written world: studies in literacy thought and action. Nova Iorque: Springer-Verlag, 1988.

. Literacy events and literacy practices: theory and practice in the New Literacy Studies. In: MARTIN-JONES, M.; JONES, K. Multilingual literacies: reading and writing different worlds. John Benjamins B.V., 2000, p. 17-29.

. Abordagens alternativas ao letramento e desenvolvimento.

Teleconferência Brasil sobre o letramento, outubro de 2003a.

.What's "new" in new literacy studies? Critical approaches to literacy in theory and practice. Current Issues in Comparative Education. Columbia: Teachers College, Columbia University, v. 5, n. 2, p. 77-99, 2003 b.

; LEFSTEIN, A. Literacy: an advanced resource book. London/New York: Routledge, 2007.

. Os novos estudos sobre o letramento: histórico e perspectivas. In: MARINHO, M.; CARVALHO, G. T. Cultura escrita e letramento. Belo Horizonte: Editora da UFMG, 2010. p.33-53.

Recebido em: 06/02/12. Aprovado em: 27/01/13.

Title: Social uses of writing: a study of literacy practices and literacy events in the experience of literacy teachers

Authors: Michelle Donizeth Euzébio; Mary Elizabeth CeruttiRizzatti

Abstract: This article focuses on the phenomenon of literacy. The study was carried out along two months with literacy teachers. It is a qualitative approach, with ethnographic implications; the study aims at answering the following questions: How are characterized the social uses of writing in these teachers' the daily life? What literacy practices and literacy events are possible to deduce/describe in their everyday life and in their work? The theoretical back-ground is Street (1984, 1988, 2003), Barton (1994), Barton, Hamilton and 
Ivanic (2000), Hamilton (2000), among other authors of the New Literacy Studies. The results indicate that the teachers mention literacy dominant events as part of your everyday life - referring to conceptions of the autonomous model of literacy. In their work, however, they mention many vernacular literacy events, referring to conceptions of the ideological model of literacy. These dissonances suggest that the teaching action is anchored in educational fads and not in theoretical constructs of this area.

Keywords: Literacy practices. Literacy events. Family sphere. Work sphere. Literacy teachers.

Título: Usos sociales de la escritura: un estudio sobre prácticas y eventos de letramento en la vivencia de profesoras alfabetizadoras Autores: Michelle Donizeth Euzébio; Mary Elizabeth CeruttiRizzatti

Resumen: Este artículo aborda el fenómeno del letramento. El estudio fue realiza-do durante dos meses con profesores alfabetizadores. Se trata de abordaje cualitativa de implicaciones etnográficas que busca responder a las siguientes cuestiones: ¿Cómo se caracterizan los usos sociales de la escritura en el cotidiano de esos profesores? ¿Qué prácticas y eventos de letramento es posible compren-der/describir en su vida cotidiana y en su trabajo? La base teórica es Street (1984, 1988, 2003), Barton (1994), Barton Hamilton e Ivanic (2000), Hamilton (2000) y otros autores de los Nuevos Estudios del Letramento. Los resultados indican que los alfabetizadores mencionan eventos de letramento dominantes como parte de su vida cotidiana - remitiendo a concepciones del modelo autónomo de letramento. En su trabajo, por otro lado, mencionan muchos eventos de letramento vernaculares, remitiendo a concepciones del modelo ideológico de letramento. Disonancias de ese orden sugieren una acción docente anclada en modismos pedagógicos y no en construcciones teóricamente consolidadas en esa área.

Palabras-clave: Prácticas de letramento. Eventos de letramento. Esfera familiar. Esfera del trabajo. Alfabetizadores. 